CLINICAL HEMORHEOLOGY, VO1.5, pp. I-III, 1985

$0271-5198 / 85 \$ 3.00+.00$ Printed in the USA.

Copyright (c) 1985 Pergamon Press Ltd. A11 rights reserved.

EDITORIAL:

SOFTWARE SURVEY SECTION

\begin{abstract}
The introduction of the new Software Survey Section to CLINICAL HEMORHEOLOGY is to encourage the open exchange of information on software programs unique to our professional field. With the rapid penetration of computers into academic and industrial institutions has come a parallel increase in the number of scientists and researchers designing their own software. The existence of much of this software remains unknown to even those of us who could most benefit from its use. We believe that it is of vital importance to our readers that such information be made available. We believe also that a professional journal is the best place to share such information. Your contribution would be most welcome.
\end{abstract}

The questionnaire on the following pages is designed to assist you in reporting on software that you may have developed or be in the process of developing. By completing this form, your information will reach thousands of your colleagues who may benefit from your work and may possibly offer suggestions for further enhancements to your software. Please complete the enclosed form and return it to:

Dr. Arpad Matrai

Klinik fur Physikalische Medizin der Universitat Munchen Innenstadt, 8000 Munchen 2

Federal Republic of Germany

We do not intend to review or comment on the contents of the questionnaire. It will be published as is in order to expedite the information cycle process. I would welcome any comments you may have.

THE EDITORS 
NAME OF JOURNAL

Title of software package:

It Is: [ ]Application program [ ]Utility [ ]0ther
Specific area
(e.g. Thermodynamics, Inventory Control)
Software developed for [name of computer(s)]
in [language(s)]
to run under [operating system]
and is available in the following media:
[ ] Floppy disk/diskette. Specify:
[ Size [ ] Magnetic tape. Specify:
$\quad$ Size
Distributed by:

Minimum hardware configuration required:

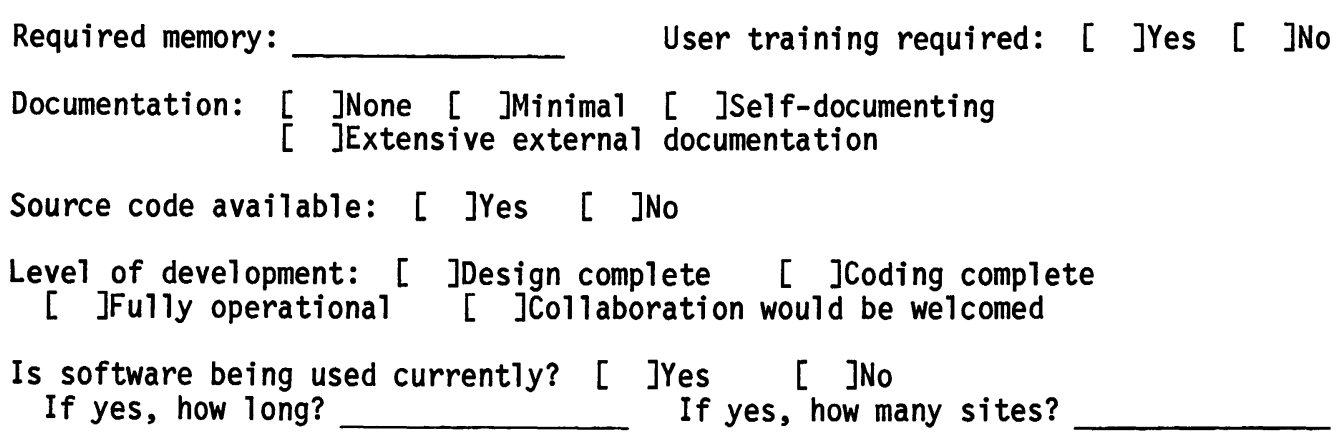

Contributor is available for user inquiries: $[$ JYes $[$ NNo

RETURN COMPLETED FORM TO:

(continued)

Dr. Arpad Matrai

Klinik fur Physikalische Medizin der Universitat Munchen

Innenstadt, 8000 Munchen 2

Federal Republic of Germany

[This Software Description Form may be photocopied without permission] 
Description of what software does [200 words]:

Potential users:

Fields of interest:

Name of

contributor:

Institution:

Address:

Telephone number:

\section{\# \# \# \# \# \#}

Reference No. [Assigned by Journal Editor]

[The information below is not for publication.]

Would you like to have your program:

Reviewed? [ ]Yes [ ]No [ ]Not at this time

Marketed and distributed? [ ]Yes [ ]No [ ]Not at this time

[This Software Description Form may be photocopied without permission] 